\title{
Axial spondylometaphyseal dysplasia
}

INSERM

\section{Source}

INSERM. (1999). Orphanet: an online rare disease and orphan drug data base. Axial spondylometaphyseal dysplasia. ORPHA:168549

Axial spondylometaphyseal dysplasia is a rare type of spondylometaphyseal dysplasia characterized by metaphyseal changes of the truncal-juxtatruncal bones associated with retinal dystrophy. Patients typically present progressive postnatal growth failure with rhizomelic shortening of the limbs, a deformed, hypoplastic thorax and retinitis pigmentosa or pigmentary retinal degeneration. Radiog raphic findings include short ribs with flared, cupped anterior ends, mild platyspondyly, lacy ilia and metaphyseal dysplasia of the proximal femora. 